\title{
EDUCAÇÃO INTERDISCIPLINAR: LIBRAS, SURDEZ E INCLUSÃO SOCIAL
}

\section{EDUCATION AND INTERDISCIPLINARITY: LIBRAS, DEAFNESS AND SOCIAL INCLUSION}

\author{
Tathianna P. Dawes ${ }^{75}$ \\ Gabriela B. Neumann Leitão ${ }^{76}$ \\ Cássia Larissa C. Lopes ${ }^{77}$
}

\begin{abstract}
Resumo
Com o destaque da inclusão no meio educacional, algumas leis garantem o direito ao acesso às escolas regulares para alunos e focam na formação do sujeito surdo bilíngue. O grupo de pesquisa Estudos do Bilinguismo: Libras e Língua Portuguesa para Surdo junto ao Projeto de Extensão Ensino de Surdos sob uma Perspectiva Bilíngue, discute e relata a realidade desses alunos surdos através de oficinas lúdicas realizadas com conteúdo do dia a dia e produzem materiais didáticos adaptados, valorizando a Libras como L1 e a Língua Portuguesa como L2. Este trabalho discorre sobre a ação dos projetos e aponta que interdisciplinaridade e inclusão são fatores importantes para o ensino-aprendizagem do aluno surdo, além de cumprir papel importante na formação do sujeito surdo bilíngue na sociedade.
\end{abstract}

Palavras-chave: Educação. Interdisciplinaridade. Inclusão Social. Educação de Surdos. Libras.

\footnotetext{
Abstract

As the educational field has emphasized the role of inclusion, there are laws that guarantee the right to regular schools for students and focus on the education of the bilingual deaf subject. The research group Grupo de Pesquisa estudos do Bilinguismo:

75 Doutoranda em Estudos de Linguagem da Pós Graduação em Estudos da Linguagem - Universidade Federal Fluminense/UFF, Mestre em Diversidade e Inclusão - Universidade Federal Fluminense/UFF, Graduada em Pedagogia - Centro Universitário Plínio Leite /UNIPLI, Coordenadora do Projeto de Pesquisa Estudos do Bilinguismos: Libras e Língua Portuguesa para o surdo - Email: tathiannadawes@id.uff.br Telefone: 21 99753-1717 - https://orcid.org/0000-0002-5573-8139

${ }^{76}$ Graduada em Licenciatura em Ciências Biológicas - Universidade Federal Fluminense/UFF - Voluntária do Projeto de Extensão Ensino de Surdos sob a Perspectiva Bilíngue - Membro do Projeto de Pesquisa Estudos do Bilinguismos: Libras e Língua Portuguesa para o surdo - Email: gabrielaneumann@id.uff.br Telefone 21 98639-8602 - https://orcid.org/0000-0002-3925-3895

77 Graduanda em Letras - Licenciatura em Letras/Grego - Universidade Federal Fluminense - UFF , Voluntária do Projeto de Extensão Ensino de Surdos sob a Perspectiva Bilíngue - Membro do Projeto de Pesquisa Estudos do Bilinguismos: Libras e Língua Portuguesa para o surdo - Email: larislo84@gmail.com - Telefone: 21979647869 - https://orcid.org/0000-0001-5112-3463
} 


\section{RevistAleph}

Libras e Língua Portuguesa para Surdo alongside with the extension Project Ensino de Surdos sob uma Perspectiva Bilíngue discuss and report the reality of deaf students through ludic workshops prepared with contents from day-to-day life and also create adapted educational material, valuing Libras as first language (L1) and Portuguese as a second language (L2). This research presents the action of both projects, the extension project and the research group, and also points that interdisciplinarity and inclusion are fundamental factors to the teaching-learning process of a deaf student and considerably important to the formation of the bilingual deaf subject in society.

Key-Words: Education. Interdisciplinarity. Social Inclusion. Deaf people education. Libras.

\section{Considerações iniciais}

Muito se tem discutido sobre a educação bilíngue para surdos e a eficiência do ensino a eles oferecido. O cenário educacional e linguístico vem ganhando força em construir caminhos de aprendizagem para atender às necessidades do aluno surdo, configurando-se em uma conquista para a comunidade surda (DAWES, 2015).

Este artigo é resultado das discussões do grupo de pesquisa Estudos do Bilinguismo: Libras e Língua Portuguesa para Surdo (EBILPS) - grupo do Diretório do CNPq e também do Projeto de Extensão Ensino de Surdos sob a Perspectiva Bilíngue, pelo Instituto de Letras da Universidade Federal Fluminense (UFF).

Assim, usa-se o espaço de pesquisa e extensão com o objetivo de criar oficinas lúdicas na perspectiva bilíngue e implementar uma nova cultura pedagógica e educacional que ofereça aos alunos surdos caminhos para se tornarem sujeitos sociais, de conhecerem melhor a si mesmo e o mundo que está ao seu redor.

Pretende-se, a partir desses estudos e das leituras teóricas de Ribeiro;Silva (2015) refletir sobre a importância de se criar práticas pedagógicas para a educação de surdos e Quadros (2019), abordar as línguas no contexto bilíngue, o ensino e a implicação da Língua Brasileira de Sinais (Libras), língua do surdo como L1, e Língua Portuguesa na modalidade escrita como L2, na educação de surdos. 


\section{RevistAleph}

A seguir, iremos abordar o panorama da história da educação de surdos no Brasil com a ideia de resgatar os fatos históricos e sua inserção na sociedade.

\section{Contexto Histórico da Educação de Surdos}

É importante ressaltar e saber sobre o contexto histórico da educação de surdos em nosso país. A primeira informação sobre ensino para surdos no Brasil, de acordo com Goldfeld (1997), se dá com a presença de Ernest Huet, professor surdo que foi trazido da França pelo imperador D. Pedro II para atender duas crianças surdas, no ano de 1855. Dois anos depois, em setembro de 1857, foi fundado o Instituto Nacional de SurdosMudos, conhecido atualmente como Instituto Nacional da Educação de Surdos (INES).

Em 1880, no Congresso Internacional de Educadores Surdos, mais conhecido como Congresso de Milão, foi decidido que o oralismo deveria ser usado como metodologia para educação de surdos; proibindo, assim, a língua de sinais por muitos anos. E, de acordo com Sacks (2010), educadores surdos não participaram desta votação.

O Oralismo, segundo Goldfeld (1997), faz com que a criança surda se integre na comunidade de ouvintes, tenha condições de desenvolver a língua oral e, para alguns profissionais que defendem essa ideia, seja o único meio de comunicação dos surdos. Sendo assim, o oralismo parte do princípio de que a surdez é uma deficiência que pode ser minimizada através da estimulação auditiva.

\footnotetext{
Essa estimulação possibilitaria a aprendizagem da língua portuguesa e levaria a criança surda a integrar-se na comunidade ouvinte e desenvolver uma personalidade como a de um ouvinte. Ou seja, o objetivo do Oralismo é fazer uma reabilitação da criança surda em direção à normalidade, à "não-surdez (GOLDFELD, 1997. p. 34).
}

O ensino oral para crianças surdas, quando colocado como prioridade, faz com que outros fatores do desenvolvimento infantil sejam esquecidos. Através da história da educação de surdos, é possível perceber que a língua oral não supre todas as 


\section{RevistAleph}

necessidades da comunidade surda. Com isso, é necessário analisar a importância da linguagem e da comunicação na construção do indivíduo, seja para transmitir informações ou pensamentos. Uma das metodologias usadas nos anos 1970 foi a Comunicação Total, com a ideia de minimizar o sofrimento dos surdos causado pelas consequências ocorridas durante a fase de oralização.

A Comunicação Total é a junção de sinais, fala, treino auditivo e leitura labial, ou seja, a língua de sinais e a língua oral usadas de forma simultânea. O termo "comunicação total" é usado para defender qualquer recurso linguístico, desde que a comunicação seja facilitada. “A Comunicação Total, como o próprio nome diz, privilegia a comunicação e interação e não apenas a língua (ou línguas)" (GOLDFELD, 1997. p. 40). Dessa forma, nenhum recurso linguístico é excluído, tais como: a oralização, a leitura, a escrita e a língua de sinais.

Em 1980 surge a proposta do bilinguismo, que foi aceita e segue em vigor até hoje. Logo, a L1 utilizada pelos surdos é a Língua Brasileira de Sinais (Libras) e a L2 é a Língua Portuguesa na modalidade escrita. Sobre a abordagem do bilinguismo, alguns autores explicam que:

A abordagem educacional por meio do bilingüismo visa capacitar a pessoa com surdez para a utilização de duas línguas: a língua de sinais e a língua da comunidade ouvinte. As propostas educacionais começam a estruturar-se a partir do Decreto 5.626/05 que regulamentou a Lei de Libras (Língua Brasileira de Sinais). Dessa forma, os surdos passaram a ter direito ao conhecimento a partir desta língua. O português é utilizado na modalidade escrita, sendo a segunda língua, e a educação dos surdos passa a ser bilíngue (KUBASKI; MORAES, 2009, p. 2).

A educação vem sofrendo mudanças com função de abranger os métodos de ensino que atendam a toda comunidade de alunos e que não restrinjam ou segreguem. A escola e os educadores têm a responsabilidade de incluir novas pedagogias voltadas para unir Língua Portuguesa e Libras como modelos de ensino, no qual os alunos 


\section{RevistAleph}

desenvolvam melhor os conhecimentos que recebem. A autora Quadros traz perspectivas acerca desse tema:

Quando me refiro ao bilinguismo, não estou estabelecendo uma dicotomia, mas sim reconhecendo as línguas envolvidas no cotidiano dos surdos, ou seja, a Língua Brasileira de Sinais e o Português no contexto mais comum do Brasil (QUADROS, 2000, p. 54).

É válido ressaltar a importância de práticas educacionais voltadas para o ensino de português como L2 na modalidade escrita para os surdos. Desse modo, é possível atentar-se ao fato que usar os mesmos materiais pedagógicos na alfabetização de surdos e ouvintes não é o ideal, uma vez que são cognitivos diferentes e que necessitam de materiais didáticos adaptados voltados para suas necessidades.

Para isto, é preciso reforçar a importância de respeitar a Libras, sua estrutura, comunicação e interação; à vista disso, a criança vai ter a oportunidade de estar inserida em contextos linguísticos, cognitivos e sociais.

A Língua Portuguesa, por sua vez, tem papel fundamental no estímulo social, pois o surdo vive em um país em que sua maioria é usuário de Língua Portuguesa e, por isso, é importante proporcionar o equilíbrio social onde todos se sintam confortáveis para a interação.

Diante desse cenário, é válido destacar que algumas medidas foram tomadas para que alunos surdos possam ser incluídos no meio educacional e social.

\section{As atribuições das ações inclusivas}

Existem documentos importantes em vigor no Brasil que favorecem a inclusão de alunos surdos no ambiente escolar que podem ser destacados: a Declaração de Salamanca (BRASIL, 1994), um documento que foi feito na Conferência Mundial sobre Educação Especial, na Espanha, no qual é reconhecida a indispensabilidade de educação para pessoas com Necessidades Educacionais Especiais; a Lei de Diretrizes e Bases da Educação Nacional (LDB, Lei n 9394/1996), que estabelece a existência da modalidade 


\section{RevistAleph}

"Educação Especial", afirmando que, se necessário, a escola deve ofertar serviços de Apoio Educacional Especializado para atender os alunos de educação especial, inclusive para os surdos, trabalhando com a proposta de estimular o uso da Libras; a Lei 10.436/2002 que reconhece a Libras como meio de comunicação e expressão legal e outros meios associados a ela (BRASIL, 2002); e o Decreto 5.626/2005, regulamentado pela Lei $10.436 / 2002$, em que Libras é definida como disciplina obrigatória nos cursos de Licenciatura e Pedagogia (BRASIL, 2005). Em 2015 é sancionada a Lei Brasileira de Inclusão da Pessoa com Deficiência - LBI, com o objetivo de promover os direitos e liberdades das pessoas com deficiência, em condições de igualdade, visando inclusão social e cidadania (BRASIL, 2015).

De acordo com as leis vistas no desenvolvimento teórico e a visão de outros autores, entende-se que o aluno surdo tem direito a uma educação inclusiva que seja bilíngue - respeitando a Libras como a primeira língua do surdo (L1) e a Língua Portuguesa como segunda língua (L2) - e adaptada ao ensino tradicional, para receber e atender todos os alunos e suas necessidades:

\footnotetext{
Além de pensar no ensino das línguas na educação bilíngue, é importante discutir as línguas no espaço educacional. As escolas normalmente estão organizadas a partir da língua portuguesa. No caso da educação bilíngue para surdos, a escola precisa ser reorganizada a partir da Libras também (QUADROS, 2019, p. 151).
}

Nas escolas, o cenário que vemos em alguns sistemas de educação, são de alunos (surdos e ouvintes) que não possuem a mesma língua e condições de ensino dentro de uma mesma sala de aula de escola regular em classe bilíngue para surdo. Isto dificulta a interação e, por conseguinte, acaba privando as crianças de se tornarem independentes e autônomas no meio educacional, social e linguístico. Dessa forma, a escola, os professores e toda a comunidade escolar têm o dever de possibilitar o convívio interativo entre os sujeitos sociais contextualizando os alunos desde os primeiros anos das propostas de inclusão. 


\section{RevistAleph}

Nesse caso, há a possibilidade de uma proposta bilíngue e uma educação voltada para contextos sociais e educacionais. Quadros (2019) faz um estudo acerca do bilinguismo, no qual reforça o papel da escola de tornar o ambiente educacional confortável e acessível, não só para os ouvintes, mas que seja inclusivo para todas as crianças que possuem suas singularidades. Além de ser de direito legal de todo aluno a oportunidade de uma educação de qualidade, inspiradora e possível.

A autora traz cinco pontos sobre o tema do bilinguismo na educação entre Libras e Língua Portuguesa que são listados a seguir:
A) legitimar a experiência visual;
B) assegurar o desenvolvimento socioemocional íntegro das crianças a partir da identificação com surdos adultos (encontro surdo-surdo);
C) criar um ambiente linguístico-social apropriado às formas particulares de processamento cognitivo e linguístico das crianças surdas;
D) garantir as possibilidades para que as crianças surdas construam uma teoria de mundo;
E) oportunizar o acesso à informação curricular e cultura (QUADROS, 2019, p. 156).

Com os pontos apresentados, é possível visualizar as especificidades que oferecem a proposta do ensino bilíngue. Por exemplo, destaca-se como as instituições devem se adaptar para receber os alunos surdos que chegam com necessidades diferentes das que vinham sendo apresentadas, por outros alunos, nas escolas regulares; assim como os educadores terem formações inclusivas e fluência na Libras, estarem preparados para isso.

De acordo com o Decreto 5.626/2005, é direito do aluno surdo ser incluído na educação bilíngue para conviver com outro surdo usuário da Libras e também estar inserido na escola comum com professor com conhecimento em Libras para garantir sua efetivação na comunicação. Em seu capítulo VII, que diz respeito à Garantia do Direito à Educação das pessoas surdas ou com deficiência auditiva do Art. 22, afirma-se: 


\section{RevistAleph}

As instituições federais de ensino responsáveis pela educação básica devem garantir a inclusão de alunos surdos ou com deficiência auditiva, por meio da organização de:

I - escolas e classes de educação bilíngue, abertas a alunos surdos e ouvintes, com professores bilíngues, na educação infantil e nos anos iniciais do ensino fundamental;

II - escolas bilíngues ou escolas comuns da rede regular de ensino, abertas a alunos surdos e ouvintes, para os anos finais do ensino fundamental, ensino médio ou educação profissional, com docentes das diferentes áreas do conhecimento, cientes da singularidade linguística dos alunos surdos, bem como com a presença de tradutores e intérpretes de Libras - Língua Portuguesa (BRASIL, 2005).

Portanto, como visto acima, as atribuições e o reconhecimento dos direitos dos surdos no Brasil são fundamentais na formação escolar inclusiva. O papel do educador e da escola é muito maior do que transmitir a mensagem que está nos livros didáticos. É ousar transformar o meio educacional em um espaço em que os alunos se sintam à vontade para aprender, construir um ambiente que atenda às necessidades de cada um e oferecer educação inclusiva de qualidade que abrace os alunos surdos.

\section{O papel da interdisciplinaridade na educação de surdos}

Como sabemos, as famílias de crianças surdas têm dificuldades para aceitar a especificidade da surdez, considerando que "95\% são filhas de pais ouvintes, os quais, em geral, desconhecem ou rejeitam a língua de sinais" (Skliar, 1997, p. 132). Os familiares acabam por tentar sempre oralizar a criança ou educá-la por meio de apontamento dos objetos, fugindo da Libras a fim de que em algum momento a surdez vá embora (o que não ocorre), além de causarem frustração, também dificultam a inserção dessa criança na sociedade e no desenvolvimento individual.

Outro fator que colabora para este distanciamento do surdo com a sociedade se dá por nascerem em um país que é predominantemente falante de Língua Portuguesa, principalmente no desenvolvimento pedagógico. Pois, se o aluno não sabe sua própria 


\section{RevistAleph}

língua materna, que é Libras, como irá se habituar à língua falada? Essas são questões que reverberam a socialização da criança surda nos primeiros contatos com a escola, o que também acaba por afastar mais ainda o surdo dos demais indivíduos. Por isso, a interdisciplinaridade vem tomando forma e se desenvolvendo com grande possibilidade na educação de surdos e na inclusão social, que é por meio dela que diferentes assuntos e temas podem ser abordados numa mesma dinâmica e proporcionar maiores concepções em uma única sala de aula.

Não se trata apenas de uma língua para aprender, porém de uma língua que marca a identidade, o eu no mundo. A primeira marca da cultura surda é sua língua; é com ela que pensa, partilha com os seus pares e dá sentido ao mundo (RIBEIRO, SILVA, 2015, p. 97).

De acordo com a autora Fazenda, interdisciplinaridade pode ser entendida como "articulação entre teorias, conceitos e ideias, em constante diálogo entre si [...] que nos conduz a um exercício de conhecimento: o perguntar e o duvidar" (FAZENDA, 1997, p. 28). A partir dessa ideia, temos como base fundamental as atribuições da escola no desenvolvimento pedagógico que estão cercando o funcionalismo linguístico.

A grande parte dos sistemas de ensino se baseia ainda em métodos tradicionais nos quais as matérias são trabalhadas separadamente. Assim sendo, a interdisciplinaridade vem para quebrar essa barreira arcaica e propor novos métodos.

Segundo os Parâmetros Curriculares Nacionais (1997, p. 6), são algumas das atribuições do ensino interdisciplinar:

- Utilizar as diferentes linguagens - verbal, musical, matemática, gráfica, plástica e corporal - como meio para produzir, expressar e comunicar suas ideias, interpretar e usufruir das produções culturais, em contextos públicos e privados, atendendo a diferentes intenções e situações de comunicação;

- Saber utilizar diferentes fontes de informação e recursos tecnológicos para adquirir e construir conhecimentos;

- Questionar a realidade formulando-se problemas e tratando de resolvê-los, utilizando para isso o pensamento lógico, a criatividade, a intuição, a capacidade de análise crítica, selecionando procedimentos e verificando sua adequação. 


\section{RevistAleph}

Utiliza-se como exemplo, o Projeto de Extensão Ensino de Surdos Sob a Perspectiva Bilíngue (este será detalhado na próxima seção). Neste projeto, são trabalhadas várias disciplinas para abordar e tornar o ensino mais didático, como por exemplo, para ensinar Matemática e Língua Portuguesa, o grupo levou massa de bolo para os alunos compreenderem o conceito de medidas e que, a partir dele, obtivessem um conhecimento lúdico sobre o tema. Na atividade, os alunos aprenderam sobre o conceito de receita, os ingredientes, como fazer o passo a passo e medidas para executá-la. Matemática e Língua Portuguesa foram usadas de forma interdisciplinar respeitando os PCN'se reforçando a presença do bilinguismo (Libras e Língua Portuguesa) na escrita; os alunos estavam, afinal, inseridos em um ambiente composto de surdos e ouvintes. Assim, possibilitou-se trabalhar os temas tradicionais com mais engajamento e métodos pedagógicos lúdicos onde a culinária esteve presente na atividade.

O ensino de surdos vem adquirindo uma crescente visibilidade com o passar dos anos por conta de direitos conquistados na área da educação, com a presença de intérpretes em salas de aula e de turmas de inclusão em escolas regulares, estas adaptadas às estratégias de práticas pedagógicas e direcionadas e adequadas para esses

alunos. Nesse caso, a ludicidade atua pedagogicamente de maneira a favorecer a educação bilíngue, interdisciplinar e abrangente, proporcionando diferentes possibilidades e saberes.

As atividades lúdicas, portanto, nos permitem experimentar, sentir, criar e recriar mundos e situações. Através dela podemos nos libertar da nossa realidade mecânica e ir muito além deste mundo, trocar experiências, viver momentos de alegria e liberdade, enfim, aprender com as situações (SCHOLZE, BRANCHER, NASCIMENTO, 2007, p.70).

No Brasil, é possível encontrar escolas regulares onde há presença do intérprete enquanto o professor ministra sua aula na Língua Portuguesa em modalidade escrita. Porém, essa questão pode ser abordada como uma dificuldade, mesmo que a intenção 


\section{RevistAleph}

seja de incluir, pois a falta de comunicação entre o aluno surdo e o professor acaba dificultando a relação. Isso ocorre por conta, por exemplo, de o professor não saber a Libras e preferir que o conteúdo ou comunicado seja transmitido pelo intérprete, diminuindo a possibilidade de uma interação direta do aluno caso ele tenha uma dúvida.

Outro fator que pode ser destacado, é a falta de materiais didáticos adaptados para os alunos surdos, que podem até possuir um livro didático, mas se depara com textos e mais textos sem que haja alguma imagem com a intenção de transmitir um pouco da realidade.

Durante os encontros do grupo de pesquisa Estudos do Bilinguismo: Libras e Língua Portuguesa para Surdo - BILIPS, lemos trechos do livro Libras (2019), de Ronice Muller de Quadros. Nele nos deparamos com depoimentos de pais que possuem filhos surdos matriculados em escolas regulares que não respeitam as políticas de inclusão. Um desses relatos chamou atenção quanto à falta de inclusão fez o aluno se sentir menosprezado pela escola e pelos colegas, o que no Brasil é um cenário comum:

Meu filho está na escola municipal e não está incluído. Às vezes disponibilizam alguém para ajudá-lo. A este alguém se referem como intérprete de língua de sinais. Eles dizem que meu filho é muito agitado e se irrita com os colegas, com a intérprete e com as professoras. Eles acusam o meu filho de problemas. No entanto, quando vejo a "suposta" intérprete de língua de sinais, vejo que ela mal consegue se comunicar com meu filho, imagino o que acontece quando ela tenta mediar a comunicação com os colegas e com a professora do meu filho. Entre seus colegas, o meu filho sente-se inferiorizado, porque não consegue ter o mesmo desempenho e sofre bullying sistematicamente. Assim, como não tem pares surdos, ele deseja ser ouvinte, para ser igual aos colegas. Ele não consegue se reconhecer como surdo, porque nesse meio ele é indesejado. Essa inclusão é um fracasso! Quando reclamo sobre a qualificação do profissional, eles me dizem que é a opção disponível, "melhor com este, do que sem ninguém". Quando tento discutir sobre a relação dele com os colegas, a situação fica ainda mais difícil, pois não reconhecem e nem compreendem o que significa ser surdo enquanto parte da comunidade surda. Eu sofro junto com meu filho, pois ele nem se reconhece entre meus amigos surdos, pois não convivemos com nenhuma outra criança surda. Ele é sozinho. Impossível manter essa situação que já se arrasta por quase cinco anos da vida do meu 


\section{RevistAleph}

filho. Vou ter que tirar meu filho da escola e mandar para outra cidade onde tem uma escola bilíngue para surdos, pois a vida do meu filho, a sua saúde psicológica, está sendo colocada em risco. Tenho certeza que, o sacrifício de ficarmos separados um do outro será compensado pelo acesso à educação com professores bilíngues e colegas surdos (depoimento de uma mãe surda [KS], sobre a experiência da escola inclusiva, 2015) (QUADROS, 2019, pág. 137).

É a partir desses e outros relatos que buscamos reforçar a importância de se discutir e reformular a educação de surdos, respeitando os direitos adquiridos ao longo dos anos e conscientizando toda a população acadêmica que a política de inclusão e bilinguismo devem estar presentes na educação diária e básica de todo aluno surdo.

Tratando-se do ensino de Ciências, a dificuldade em relação à escassez de sinais para a área, mesmo que atualmente tenham pesquisas para novos sinais, ainda provoca a necessidade de se ampliar o vocabulário para que determinados conceitos sejam passados da melhor maneira para os alunos surdos. Ao se usar estratégias e metodologias com essa perspectiva, é possível destacar a importância de fatores como o uso do aspecto visuoespacial e o atrelamento da língua portuguesa vinculada às outras áreas do conhecimento.

A importância do uso do visual é considerada a partir do momento em que se usa a Libras, uma língua completamente visual, com ênfase nos sinais, expressões faciais e corporais. Sendo assim, as metodologias que exploram o aspecto visuoespacial são de grande proveito para formação do conhecimento do aluno surdo. Já o uso da Língua Portuguesa, mesmo que seja em outra área do conhecimento como Ciência, História, Geografia, etc, faz com que aprimore a L2 desse aluno, trabalhando a escrita e conceitos desses temas.

Com isso, nota-se que as estratégias e metodologias para promover uma educação mais adequada às necessidades dos alunos surdos estão cada vez mais evoluindo, cabe agora aos educadores ampliarem seus conhecimentos para que seja possível uma educação inclusiva, bilíngue, interdisciplinar e, principalmente, construtiva; sabemos que o papel da escola é assegurar que os alunos estejam 


\section{RevistAleph}

acompanhando as evoluções cognitivas, linguísticas e educacionais da sociedade em que fazem parte.

\section{Ensino de Surdos sob a perspectiva Bilíngue: uma proposta construtiva}

O Projeto de Extensão de Ensino de Surdos sob a Perspectiva Bilíngue (EESB), criado em 2016, no Instituto de Letras pela Universidade Federal Fluminense, tem como objetivo criar oficinas lúdicas no qual se oferecem aos alunos surdos duas línguas: a Libras (a língua materna do surdo como L1) e a Língua Portuguesa (a língua oficial de seu país, como L2). Acrescenta-se a isto a busca por melhores condições de comunicação, de domínio da linguagem e organização de pensamento que viabilizarão a leitura e a escrita para um melhor desenvolvimento no processo de letramento no contexto da diversidade e inclusão.

A educação de surdos, que é oferecida pelo ambiente escolar de ensino regular, não é satisfatória aos alunos surdos, por se tratar de uma maioria linguística formada por ouvintes, falantes de uma língua oral. A proposta bilíngue que é oferecida compreende a Libras, a língua materna do surdo, e a Língua Portuguesa, a Língua oficial de nosso país. A criança surda por não "viver" a Língua Portuguesa de forma espontânea, por não possuir a capacidade sensorial-auditiva e, assim, não perceber e registrar na memória tudo que nos cerca, produzindo desta forma acervo linguístico e vocabulário, terá uma enorme dificuldade quanto à interpretação de textos se não for

trabalhada a Língua Portuguesa. É preciso desenvolver o trabalho voltado para o crescimento da linguagem escrita e do pensamento.

A Libras é utilizada como suporte para a Língua Portuguesa, ampliando, desta forma, as possibilidades de aquisição de vocabulário e de formação de subjetividades. As formas de aprendizagem na leitura e na escrita possibilitam a estes indivíduos viverem interagindo com seus pares, a fim de aprimorar seu conhecimento na área do ensino bilíngue. 


\section{RevistAleph}

\section{Metodologia}

O Ensino de Surdos sob a Perspectiva Bilíngue - (EESB) é um projeto social coordenado pela professora Tathianna Dawes, da Universidade Federal Fluminense. O EESB tem sete surdos inscritos na faixa etária de 6 a 22 anos, todos são usuários de Libras. Contamos, também, com a participação de voluntários (alunos) da graduação e pós- graduação da UFF e de outras instituições de diversos cursos para serem monitores bilíngues. A oficina do projeto ocorre uma vez por semana, nos turnos da manhã e tarde, com duração de 2 horas por grupo, no contraturno da escola.

O Grupo de Pesquisa "Estudos do Bilinguismo: Libras e Língua Portuguesa para Surdo" (EBILIPS), também coordenado pela profa Tathianna Dawes, baseia-se em discutir embasamentos teóricos da área de educação de surdos e, como o grupo é composto por alguns voluntários do EESB, relatar as experiências das práticas com os alunos surdos do projeto. Os encontros ocorrem a cada 15 dias, com 2 horas de duração. O EBILIPS tem o papel de fazer a ponte entre as oficinas e as teorias educacionais, discutir e elaborar conceitos e análises sobre os alunos e suas necessidades demonstradas durante as oficinas. Ou seja, o Grupo de Pesquisa e o Projeto de Extensão estão unidos para proporcionar uma metodologia teórica e prática.

Ao se considerar os direitos e leis que regem a educação de surdos no Brasil em escolas regulares, o projeto tem o propósito de proporcionar uma série de oficinas lúdicas que provoquem a criatividade e a autonomia dos alunos surdos beneficiados. Com atividades que visem à necessidade individual, no qual a singularidade de cada aluno, demonstrada durante as oficinas, é usada para a criação de novos materiais didáticos adaptados. Dessa forma, os materiais objetivam reconstruir conceitos importantes vistos nas escolas, reforçar as necessidades e reconstruir o contexto da educação juntamente com os saberes de quem a recebe.

As propostas educativas do projeto não objetivam somente ao currículo mínimo imposto pelo Ministério da Educação, visam igualmente proporcionar aos indivíduos 


\section{RevistAleph}

maiores condições de vida social, de se tornarem sujeitos independentes e de alcançarem saberes em que na escola regular não é capaz de olhar com atenção individual a cada aluno. Assim, o projeto tem o propósito de criar oficinas pedagógicas que estimulem o cognitivo, linguístico e social, levando para o ambiente onde ocorre no projeto as atividades são elaboradas em Libras e Língua Portuguesa (na modalidade escrita), para que sejam compreendidas no mesmo contexto, conectando conhecimento e ensino de língua ao cotidiano do aluno.

Por isso, a importância do projeto de extensão para com a comunidade possibilita essa união entre a pesquisa científica e a formação de professores capacitados a observar as demandas individuais e transformar o ambiente da educação em múltiplos saberes.

As práticas pedagógicas do projeto têm o cuidado de transformar o ambiente da sala de aula em um lugar de descobertas, se o aluno, por exemplo, é fluente em Libras, mas pouco sabe sobre Língua Portuguesa escrita, os voluntários se atentam a essa questão e criam atividades em que a Língua Portuguesa será o objeto de estudo naquele momento. Como de natureza igual, ocorre com outras disciplinas, como Matemática, Ciências, Geografia, História, Educação Ambiental entre outras. Sendo assim, "as oficinas desempenham diversas funções, dentre elas: estimular a curiosidade e a criatividade dos alunos através de estímulos sensoriais e despertar um interesse pela construção pessoal do próprio conhecimento" (MONTEIRO, 2017. p.7) Contudo, é preciso salientar que também são trabalhadas atividades que buscam incitar o pensamento crítico, social e criativo de maneira individual.

\section{Resultados}

O Projeto de Extensão Ensino de Surdos Sob a Perspectiva Bilíngue (EESB) oferece oficinas de inclusão para alunos surdos da rede pública de ensino. Ademais, junto com outros voluntários/alunos do projeto, também participamos de eventos 


\section{RevistAleph}

acadêmicos voltados para a formação dos licenciandos. Dessa forma, abaixo iremos reforçar alguns eventos de nossas participações, contribuições e produções publicadas; além de dar ênfase à importância da interdisciplinaridade e como usamos essa ferramenta à nosso favor para os atendimentos e na nossa formação acadêmica.

Acreditamos que o desenvolvimento da leitura e da escrita é um processo de significados para que o aluno surdo se permita pensar e expressar suas ideias, opiniões e sentimentos em tempo hábil. Quadros (2006) afirma que o processo de letramento vai sendo delineado com base neste processo de descoberta da própria língua e de relações expressadas por meio desta:

A idéia não é simplesmente uma transferência de conhecimentos da primeira língua para a segunda língua, mas sim um processo paralelo de aquisição e aprendizagem em que cada língua apresenta seus papéis e valores sociais representados (QUADROS, 2006, pág.24).

Sempre nos preocupamos com as abordagens que levamos para as oficinas, propondo atividades que estejam presentes no cotidiano e oferecendo ludicidade em temas que agreguem ao conhecimento prévio dos alunos participantes. Baseamo-nos na proposta de usar a Libras como L1 e trazemos para o contexto social e educacional a L2 (Língua Portuguesa), de modo a reforçar o bilinguismo e incluir o aluno surdo no espaço em que está inserido.

Uma das autoras deste artigo aplicou uma oficina lúdica da Língua Portuguesa, que consistia em utilizar livros de Literatura que só continha imagens, para que, dessa forma, o aluno usasse sua própria criatividade e o aspecto visual como suporte e inspiração para escrever a história que visualizava ao passar as páginas. Despertou-se a criatividade individual, conhecimentos de mundo, ritmo de leitura e imaginação. A leitura visual resulta em narrativa escrita em Língua Portuguesa por estudantes que possuem Libras, assim o bilinguismo fornece base para alcançar novos saberes:

Cada estímulo é um novo desafio e novo nível de abstração na mente do aluno que está sendo inserido no contexto da língua portuguesa, e 


\section{RevistAleph}

é justamente esse ponto que busco incitar, é mostrar como a abstração pode se tornar fácil, o que mais pra frente gera autonomia na hora da escrita, liberdade de expressão e domínio da língua (LOPES, DAWES, 2019, p. 45).

O estímulo é feito por meio de uma conversa, troca de ideias e experiências. Ao compreender e transmitir mensagens, os educandos são capazes de responder e formular perguntas, escrever suas interpretações e construir a história. Assim sendo, fazemos a implementação da Língua Portuguesa sem deixar de respeitar a escrita cultural da Língua Brasileira de Sinais.

Ao sair do contexto da sala de aula e abrir as práticas pedagógicas para outros ambientes que reforçam a importância da interdisciplinaridade, o projeto também realizou uma visita ao Aquário Marinho do Rio de Janeiro (AquaRio), onde foi possível apresentar aos alunos outras formas de vida, ver e entender a variedade de seres vivos marinhos existentes e o porquê possuem esse modo de vida. A partir dessa visita, foi possível a realização de uma atividade lúdica, na qual combinou-se o uso do aspecto visual através de imagens, Libras, Português escrito e ensino de Ciências. Foi possível também abordar os conteúdos apresentados, dando também a oportunidade de apresentar algo novo, responder algumas dúvidas e mostrar um conceito de forma correta, antes visto de forma equivocada. Esta atividade também foi apresentada por uma das autoras, que é formada em Biologia e fez sua monografia no projeto (EESB):

[...] um dos fatores principais no processo de ensino-aprendizagem é a interação de uma informação nova ou material novo com a estrutura preexistente, o que me permitiu observar que quando passávamos por um local do aquário com algum ser vivo que as alunas já haviam visto, por exemplo, em algum desenho animado e que ali ele era verdadeiro, elas apontavam dizendo que conheciam, trazendo algum conhecimento prévio. Porém, outro exemplo de uma situação assim é quando elas viram o tubarão e foi perguntado qual era o tipo de alimento dele, elas responderam "pessoas", ou seja, era um conhecimento prévio, mas equivocado (LEITÃO, 2019 p. 27).

Ainda sobre trabalhos na área de Ciências, o projeto também participou de duas oficinas em que os resultados foram duas monografias, nas quais foram apresentados 


\section{RevistAleph}

conteúdos presentes no dia a dia dos alunos, porém com pouco ou nenhum conhecimento por parte deles. Com isso, novos conceitos foram abordados e exemplificados com atividades que utilizavam o aspecto visual para esses conceitos.

O trabalho intitulado "Oficinas interativas para o ensino de Ciências para crianças e adolescentes surdos: conhecendo o corpo humano" foi escrito por uma das voluntárias do projeto e visava apresentar o corpo humano através de oficinas com modelos didáticos dos sistemas que compõem o corpo. Como parte do trabalho, também incluiu-se visitar o Laboratório de Ciências, outro espaço educacional para maior exploração do conhecimento desses alunos. A autora Monteiro esclarece:

[...]o uso de modelos didáticos é muito importante não só pelo estímulo visual, mas também por abranger outros sentidos como o tátil, que é imprescindível no ensino e aprendizagem do aluno surdo (MONTEIRO, 2017 p. 33).

Outro trabalho nomeado "Ensino de ciências para crianças e jovens surdos: uma abordagem sobre organismos invisíveis a olhos nus" foi escrito por outra voluntária do projeto e tinha como objetivo apresentar aos alunos surdos a existência de microrganismos no dia a dia. Também valorizou-se o uso do aspecto visual e apresentou-se nomes e conceitos novos, assim como foi explicado, por exemplo, a importância da higienização das mãos. Uma das oficinas contou com a visita ao Laboratório de Ciências, onde os alunos puderam observar esses microrganismos no microscópio. Segundo Henriques:

Além de destacar a importância da língua de sinais para a educação de surdos, o aspecto visuoespacial também deve receber a devida atenção, podendo auxiliar através do uso de metodologias adequadas. Exemplificando tal afirmação, vimos que os alunos participantes do projeto realizaram uma visita a um laboratório, utilizaram instrumentos que instigavam à visão, realizaram um experimento, manusearam produtos e construíram cartazes, de forma a fugir de uma metodologia extremamente tradicional e a favorecer a aprendizagem significativa dos mesmos através do uso da visão e do reconhecimento espacial (HENRIQUES, 2018 p. 46). 


\section{RevistAleph}

Através de visitas a espaços educacionais não formais, pudemos valorizar o uso do aspecto visual com a intenção de apresentar aos alunos surdos conteúdos de seu cotidiano. A Casa da Descoberta, por exemplo, situada no campus Praia Vermelha da UFF, levou os alunos surdos a tocarem nos experimentos de Física, possibilitando um maior contato com a realidade.

O ensino de Matemática também fez presença no projeto com a atividade "caixinha matemática", que consistiu em uma proposta de desenvolver o raciocínio lógico e facilitar a aprendizagem da disciplina. Esta atividade foi igualmente importante para reforçar os sinais numéricos em libras e a escrita em Língua Portuguesa. O material usado foram 10 caixinhas de fósforo numeradas, de 1 a 10, onde em cada uma delas continham botões representando a quantidade referida ao número:

A atividade foi dividida em dois momentos. No primeiro, os objetos foram retirados das caixinhas de modo que os alunos os colocassem de volta de acordo com cada número correspondente. Em um segundo momento, utilizamos os objetos das caixinhas para trabalhar as noções de adição e subtração. Assim, notou-se que os alunos conseguiram reconhecer os números, as sequências numéricas e o aprimoraram a capacidade de efetuar operações, demonstrando que este material pode ser uma ferramenta valiosa para o ensino bilíngue de matemática, principalmente nas séries iniciais (BASTOS, SANTOS, DAWES, 2017 p. 93).

Seguindo nesta mesma área, mais um trabalho realizado com o EESB foi o "biscoitos matemáticos", no qual se tinham contas de multiplicação escritas nos biscoitos, faziam-se sorteios com eles para cada aluno e era preciso responder o resultado daquela conta. Como corroboram os autores:

O caráter lúdico em atividades, em específico na matemática podem ser utilizadas para introduzir ou aprofundar conceitos, diminuir os bloqueios e receios dos alunos quanto à disciplina, podendo também potencializar a capacidade educativa de diferentes atividades (MAGALHAES, SILVA, DAWES. 2017 p. 98). 


\section{RevistAleph}

Além disso, os voluntários oferecem oficinas voltadas para sua área de pesquisa. A título de exemplos, são aplicadas atividades de ciências, matemática, geografia e questões sociais. Dessa forma, além de oferecermos uma educação bilíngue, também faz-se uso da interdisciplinaridade para que o aluno tenha acesso, cultura e materiais pedagógicos voltados totalmente para suas singularidades.

\section{Considerações finais}

Através de nossas experiências, o projeto Ensino de Surdos Sob a Perspectiva Bilíngue - EESB e a equipe do grupo de pesquisa Estudos do Bilinguismo: Libras e Língua Portuguesa para Surdos - EBILIPS se dedicam a pesquisar e produzir materiais didáticos adaptados voltados para as necessidades dos discentes surdos que recebemos no projeto. Cada voluntário tem a missão de desenvolver materiais que cumpram o papel de educador bilíngue, que forneça a alfabetização, o letramento, o ensino de todas as matérias presentes no currículo escolar e, principalmente, a inclusão social.

O projeto, além das atividades citadas, também ampliou seu alcance em 2019 participando do evento UFF nas Praças, que consiste em levar todos os projetos de extensão que acontecem dentro da universidade para as ruas de Niterói (RJ), a fim de que toda população conheça e reconheça o trabalho feito pelos acadêmicos. Com esse evento, foi possível mostrar todo nosso material produzido pelos voluntários, divulgar mais o projeto e buscar novos alunos surdos que não o conheciam e agora podem participar.

Outro evento em que o projeto participou no ano de 2018 e 2019 foi a Semana de Desenvolvimento Acadêmico, voltado para que os estudantes da universidade participem de oficinas desenvolvidas por projetos de extensão e promovam um maior reconhecimento das pesquisas que ocorrem ao longo do ano na Universidade Federal Fluminense. Cada voluntário confecciona um novo material didático lúdico e interdisciplinar para que se reconheça a educação de libras juntamente com o 


\section{RevistAleph}

bilinguismo, com o intuito de ampliar seus saberes sociais e enriquecer sua formação, acrescentando conhecimentos de uma educação inclusiva.

É importante salientar que a educação de surdos deve ser pensada em um conjunto de necessidades e que seja abrangente a todos que irão recebê-la. Por isso, a ludicidade e a interdisciplinaridade devem ser cogitadas e devem fazer parte de todo material pedagógico para que os alunos obtenham o maior índice de conhecimentos necessários à sua formação.

Pensar em uma educação inclusiva é aquela na qual todas as partes (alunos) são beneficiadas com o direito à melhor formação, é tirar o aluno surdo do isolamento, do silêncio e mostrá-lo o mundo de possibilidades que o espera.

A educação é o caminho para que as famílias de filhos com necessidades especiais não se sintam mais envergonhadas, mas que percebam seus direitos, que abracem o novo caminho que surge e aprendam a se comunicar com seus filhos usando a língua a qual fazem parte.

Nota-se, pois, que é preciso fomentar a discussão no ambiente pedagógico para que a educação se torne, cada vez mais, acessível entre toda comunidade educacional; tornar a Língua Portuguesa capaz de abraçar a todos os alunos independente de suas necessidades; e que o bilinguismo, entre a Libras e a Língua Portuguesa na modalidade escrita, seja aberto a reconhecer seus fatores motivacionais, pedagógicos, estruturais, literários, dinâmicos e, o principal, comunicativo.

\section{Referências}

BASTOS, Aline Benvinda; SANTOS, Juliana Felicidade Teixeira dos; DAWES, Tathianna Prado. 0 Processo de Alfabetização Matemática na Perspectiva bilíngue - Anais do I Encontro de Professores Bilíngues de Surdos, UFF; 2017.

DAWES, Tathianna Prado. Produção de material didático: comunicação, interação e estimulação da LIBRAS no museu itinerante Ciências Sob Tendas. Dissertação. (Mestrado em Diversidade e Inclusão) - Universidade Federal Fluminense, 2015 


\section{RevistAleph}

BRASIL. Declaração de Salamanca e Linha de ação sobre necessidades educativas especiais. Brasília: Coordenadoria Nacional para Integração da Pessoa Portadora de Deficiência, 1994.

BRASIL Lei no. 9.394 de 20 de dezembro de 1996. Diretrizes e Bases da Educação Nacional. Diário Oficial da República Federativa do Brasil. Brasília, 1996.

BRASIL Lei no. 10.436 de 24 de abril de 2002. Dispõe sobre a Língua Brasileira de Sinais - Libras e dá outras providências. Diário Oficial da República Federativa do Brasil. Brasília. 2002.

BRASIL Decreto no 5.626 de 22 de dezembro de 2005. Regulamenta a lei no 10.436, de 24 de abril de 2002. Diário Oficial da República Federativa do Brasil. Brasília, 2005.

BRASIL Lei no. 13.146 de 6 de julho de 2015. Lei Brasileira de Inclusão da Pessoa com Deficiência. Diário Oficial da República Federativa do Brasil. Brasília. 2015

FAZENDA, Ivani. A Pesquisa em educação e as transformações do conhecimento. 2.ed. Campinas: Papirus, 1997.

GOLDFELD, M. A Criança surda: linguagem e cognição numa perspectiva sociointeracionista. 2. ed. São Paulo: Plexus, 1997.

HENRIQUES, Maíra Soares. Ensino de Ciências para crianças e jovens surdos: uma abordagem sobre organismos invisíveis a olhos nus - Monografia (Licenciatura em Ciências cias Biológicas) - Universidade Federal Fluminense, 2018

KUBASKI, C; MORAES, V. P; O Bilinguismo como proposta educacional para crianças surdas; IX Congresso nacional de educação- EDUCERE; III Encontro sul brasileiro de psicopedagogia; PUCPR, 2009.

LEITÃO, Gabriela Bastos Neumann. 0 uso de espaços educacionais não formais no ensino de Ciências para jovens e adultos surdos: Conhecendo o fundo do mar.

Monografia (Licenciatura em Ciências cias Biológicas) - Universidade Federal Fluminense, 2019

LOPES, Cássia Larissa Conceição; DAWES, Tathianna Prado. A importância da produção textual no aprendizado de língua portuguesa como L2, III Jornada acadêmica de libras, UFF, 2019.

MAGALHÃES, Cleyton Ribeiro; SILVA, Rayanne Araújo Mendes da, DAWES, Tathianna Prado. Uma proposta lúdica de ensino de matemática para alunos surdos em contexto bilíngue Anais do I Encontro de Professores Bilíngues de Surdos, Universidade Federal Fluminense; 2017.

MEC, Parâmetros Curriculares Nacionais: apresentação dos temas transversais, ética / Secretaria de Educação Fundamental. - Brasília: MEC/SEF, 1997. 


\section{RevistAleph}

MONTEIRO, Letícia Fernandes Alvarenga. Oficinas interativas para o ensino de ciências para crianças e adolescentes surdos: conhecendo o corpo humano - Monografia (Licenciatura em Ciências cias Biológicas) - Universidade Federal Fluminense, 2017

QUADROS, Ronice Müller de. Ideias para ensinar português para alunos surdos Brasília, MEC, SEESP, 2006.

QUADROS, Ronice Müller de. Linguística aplicada e Libras. In: Libras. 1. ed. São Paulo: Parábola, 2019.

QUADROS, Ronice Müller de. Alfabetização e o ensino da língua de sinais. Textura, Canoas $\mathrm{n}$ ㅇ, 2000.

RIBEIRO, Tiago, SILVA. Aline Gomes da. Leitura e escrita na educação de surdos: das políticas às práticas pedagógicas. Coleção Educação e Surdez, Wak Editora: Rio de Janeiro, 2015

SACKS, O. Vendo vozes: uma viagem ao mundo dos surdos. Tradução: Laura Teixeira Mota. São Paulo: Companhia de Bolso, 2010.

SKLIAR, C. (Org.). Educação e exclusão: abordagem socioantropológica em Educação Especial. Porto Alegre: Mediação, 1997.

SCHOLZE, Darlene, BRANCHER, Vantoir Roberto, NASCIMENTO, Cláudia Terra do. O papel da ludicidade no processo de aprendizagem infantil. Revista da Faculdade de Educação, ano V, no 7/8, Jan./Dez., 2007.

Data do envio: 08/09/2020

Data do aceite: 08/04/2021 